\title{
The effects of FES cycling combined with virtual reality racing biofeedback on voluntary function after incomplete $\mathrm{SCl}$ : a pilot study
}

Lynsey D. Duffell ${ }^{1 *}$, Sue Paddison ${ }^{2}$, Ahmad F. Alahmary ${ }^{3}$, Nick Donaldson ${ }^{1}$ and Jane Burridge ${ }^{3}$

\begin{abstract}
Background: Functional Electrical Stimulation (FES) cycling can benefit health and may lead to neuroplastic changes following incomplete spinal cord injury (SCI). Our theory is that greater neurological recovery occurs when electrical stimulation of peripheral nerves is combined with voluntary effort. In this pilot study, we investigated the effects of a one-month training programme using a novel device, the iCycle, in which voluntary effort is encouraged by virtual reality biofeedback during FES cycling.

Methods: Eleven participants (C1-T12) with incomplete SCI (5 sub-acute; 6 chronic) were recruited and completed 12-sessions of iCycle training. Function was assessed before and after training using the bilateral International Standards for Neurological Classification of SCI (ISNC-SCI) motor score, Oxford power grading, Modified Ashworth Score, Spinal Cord Independence Measure, the Walking Index for Spinal Cord Injury and $10 \mathrm{~m}$-walk test. Power output (PO) was measured during all training sessions.
\end{abstract}

Results: Two of the 6 participants with chronic injuries, and 4 of the 5 participants with sub-acute injuries, showed improvements in ISNC-SCI motor score > 8 points. Median (IQR) improvements were 3.5 (6.8) points for participants with a chronic SCl, and 8.0 (6.0) points for those with sub-acute SCl. Improvements were unrelated to other measured variables (age, time since injury, baseline ISNC-SCI motor score, baseline voluntary PO, time spent training and stimulation amplitude; $p>0.05$ for all variables). Five out of 11 participants showed moderate improvements in voluntary cycling PO, which did not correlate with changes in ISNC-SCI motor score. Improvement in PO during cycling was positively correlated with baseline voluntary $\mathrm{PO}\left(\mathrm{R}^{2}=0.50 ; p<0.05\right)$, but was unrelated to all other variables $(p>0.05)$. The iCycle was not suitable for participants who were too weak to generate a detectable voluntary torque or whose effort resulted in a negative torque.

Conclusions: Improved ISNC-SCI motor scores in chronic participants may be attributable to the iCycle training. In sub-acute participants, early spontaneous recovery and changes due to iCycle training could not be distinguished. The iCycle is an innovative progression from existing FES cycling systems, and positive results should be verified in an adequately powered controlled trial.

Trial registration: ClinicalTrials.gov, NCT03834324. Registered 06 February 2019 - Retrospectively registered, https:// clinicaltrials.gov/ct2/show/NCT03834324. Protocol V03, dated 06.08.2015.

Keywords: Biofeedback, Cycling, Functional electrical stimulation, ISNC-SCI motor score, Spinal cord injury, Virtual reality

\footnotetext{
* Correspondence: I.duffell@ucl.ac.uk

${ }^{1}$ Department of Medical Physics \& Biomedical Engineering, University College

London, Malet Place Engineering Building, Gower Street, London WC1E 6BT,

UK

Full list of author information is available at the end of the article
}

(c) The Author(s). 2019 Open Access This article is distributed under the terms of the Creative Commons Attribution 4.0 International License (http://creativecommons.org/licenses/by/4.0/), which permits unrestricted use, distribution, and

reproduction in any medium, provided you give appropriate credit to the original author(s) and the source, provide a link to the Creative Commons license, and indicate if changes were made. The Creative Commons Public Domain Dedication waiver (http://creativecommons.org/publicdomain/zero/1.0/) applies to the data made available in this article, unless otherwise stated. 


\section{Background}

Neurological recovery following Spinal Cord Injury (SCI) is thought to take place during the first few months following injury. Later, functional improvement may be due to normal motor learning and muscle strengthening [1]. Factors that are critical to neuroplasticity are timing and intensity of therapy [2,3]. Non-primate studies have shown that neural re-organisation occurs after 400 repetitions of a reaching movement but not 60 [4], such intensity is unlikely to be achieved through conventional therapy. Rehabilitation technologies are becoming more widely used to increase number of repetitions, for example partial bodyweight support treadmill training and robotic devices. Despite their theoretical potential, evidence for effectiveness is equivocal [5] and costeffectiveness is limited because they are expensive and require physiotherapists' support.

Functional Electrical Stimulation (FES)-cycle ergometry is a low-cost, potentially home-usable alternative [6]. FES is a means of producing contractions in muscles and is applied via electrodes either on the skin or implanted. FES has been found to have a therapeutic or "carry-over" effect on gait re-education and lower limb strengthening in studies with stroke and SCI patients [7-10]. Ambrosini et al. [11] tested FES cycling exercise in a double-blind randomised trial as a therapy after stroke: FES cycling was compared with a placebo intervention (passive cycling with electrodes attached without delivering any stimulation current). The FES participants showed statistically significant improvements in motor power of the paretic lower extremity compared with placebo subjects. FES participants also experienced improved walking speed, which was maintained 4 months after the treatment, however this parameter was not statistically significantly different compared with the placebo group.

McDonald et al. [12] described a single case study of functional recovery after a 3-year program of activity ("activity-based recovery") incorporating FES muscle conditioning and FES cycling: the individual improved from ASIA Imapirment Scale (AIS) Grade A to AIS Grade C. Later, the same group reported a study with 45 chronic subjects, 25 of whom used FES for between 3 and 168 months (mean 29.5 months) and 20 controls, matched by age, gender, injury level, injury severity, and duration of injury, who received range of motion and stretching. The average functional improvements in International Standards for Neurological Classification of SCI (ISNC-SCI) motor score were 8.1 (SD 10.0) for the FES group, which they defined as a clinically important gain in neurological function, and 0.6 (SD 6.5) for the controls [13].

Yaşar et al [14] used FES-cycling to train 10 people with incomplete (AIS C or D) SCI who were all able to walk 10 $\mathrm{m}$ with a cane or walker (all were between 24 and 33 months post-injury). Their outcome measures included ISNC-SCI motor score. The therapy sessions were of $1 \mathrm{~h}$, 3 times per week for 3 months and outcome measures were made at the end of the therapy and again 3 months later. The participants were instructed not to make any voluntary effort. Average motor scores improved by 1.7 after the therapy and 4.7 at follow up. There were also significant improvements in spasticity, Functional Independence Measure (FIM) and oxygen consumption while walking. However, these authors commented that there was no control group so the improvement might not have been due to the electrical stimulation.

Greater changes in corticospinal transmission, have been demonstrated when nerve stimulation from two different sources is synchronised, (termed associated stimuli) for example repetitive Transcranial Magnetic Stimulation (TMS) of the motor cortex paired with peripheral stimulation of the common peroneal (to cause contraction of the ankle dorsiflexor muscles) rather than when each stimulation is provided asynchronously [15, 16]. This observation may explain why FES during walking in patients with central nervous system lesions, has a therapeutic effect when stimulation of the common peroneal nerve coincides with the person's natural attempt to dorsiflex their ankle - i.e. voluntary drive from the motor cortex [17]. The mechanism is not fully understood, but could be due to neuroplastic changes within the central nervous system [18-20], involving a Hebbian type learning effect from concurrent voluntary neural drive and electrical muscle stimulation: antidromic electrical impulses may raise the resting potential of the anterior horn cells, so that they are more likely to discharge thus providing pre and post synaptic activity and 'learning opportunities' when accompanying voluntary activity [18]. Most FES cycles and motor-assisted ergometers (e.g. RT300) do not capitalise on this effect because no incentive is given to encourage the patient to use voluntary effort to turn the pedals.

To our knowledge, voluntary intention, combined with stimulation during purposeful cycling, and providing feedback based only on the voluntary effort, has not been tested. This may be because of the technical difficulty of reliably separating voluntary effort from FES-activated muscle. In earlier work in our lab, we attempted to estimate the torque from the quadriceps electromyography (EMG) in able-bodied subjects while stimulating the muscle and blanking the stimulus artefact, but because of the high variability of the RMS value, this averaging had to be continued for many revolutions of the pedals to reach a sufficient confidence level, and therefore could not be used for real-time biofeedback where the speed must quickly respond to changes in voluntary effort [21]. Therefore we tackled the problem differently. Stimulation was applied only on alternate revolutions of the pedals so that the average torque 
during the non-stimulation revolution represented voluntary effort. It was assumed that the effort was the same during revolutions with stimulation and those without. In order to maximise voluntary effort, the torque signal from non-stimulated revolutions was used as the input to a commercially available virtual reality (VR) cycle racing game. This approach avoids the practical complication of EMG, and the differences between patients in the muscles paralysed by iSCI. It is essential for practical home-use of the iCycle.

(a)

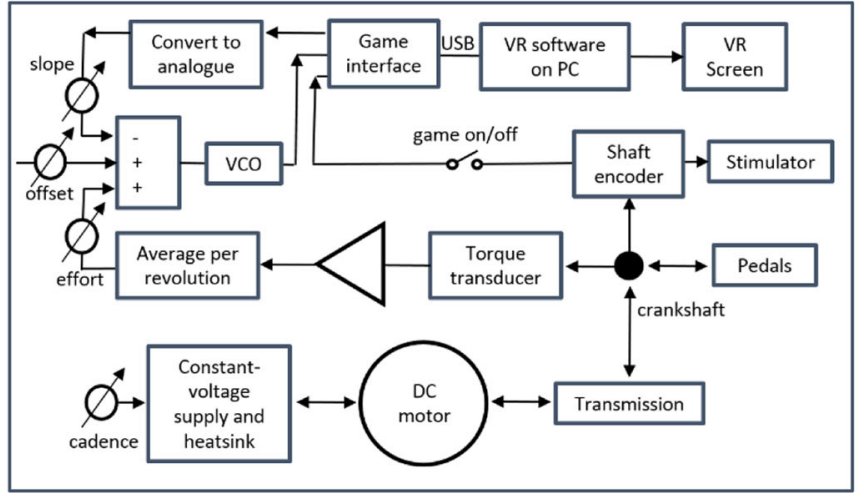

(c)
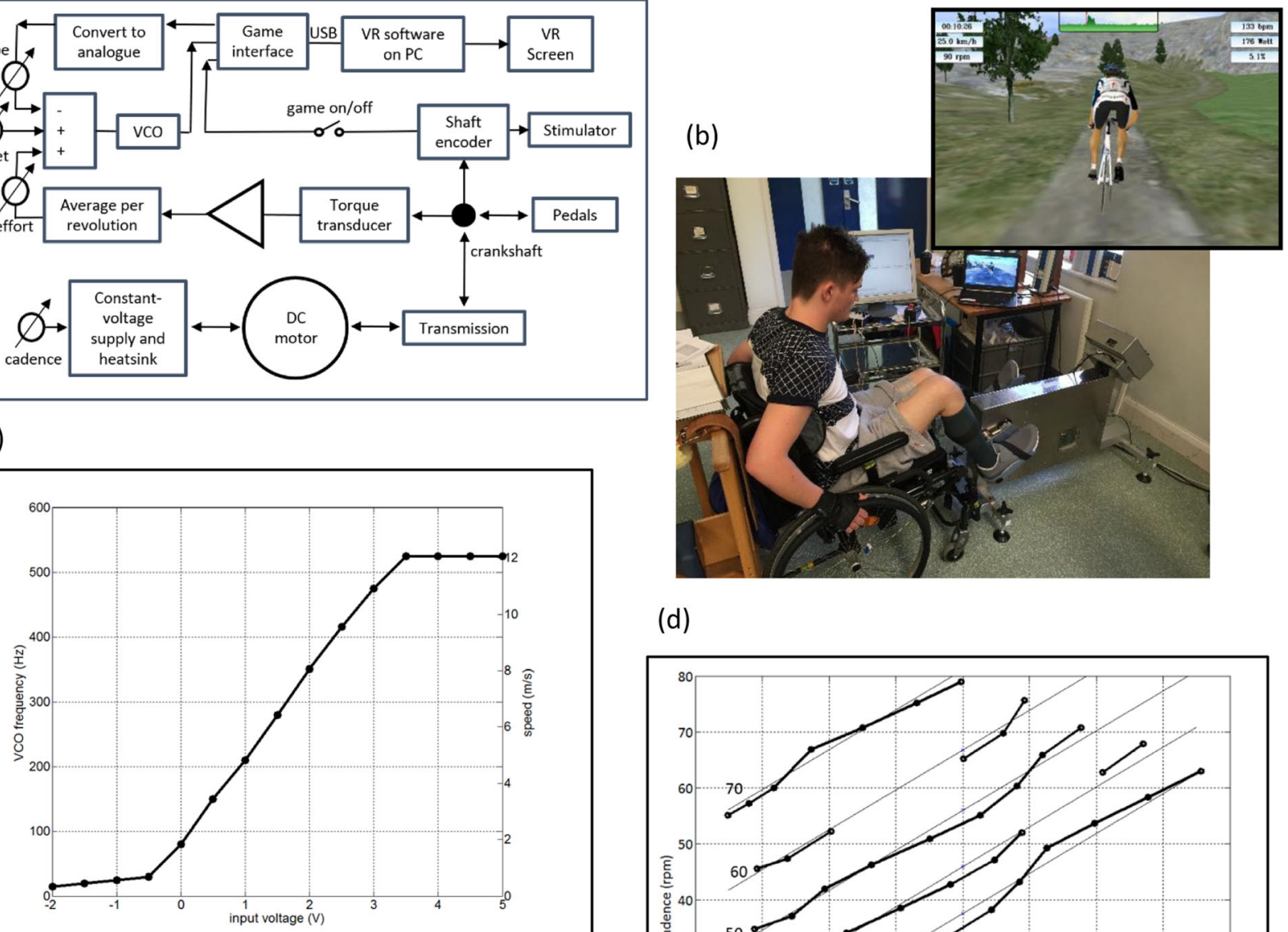

(d)
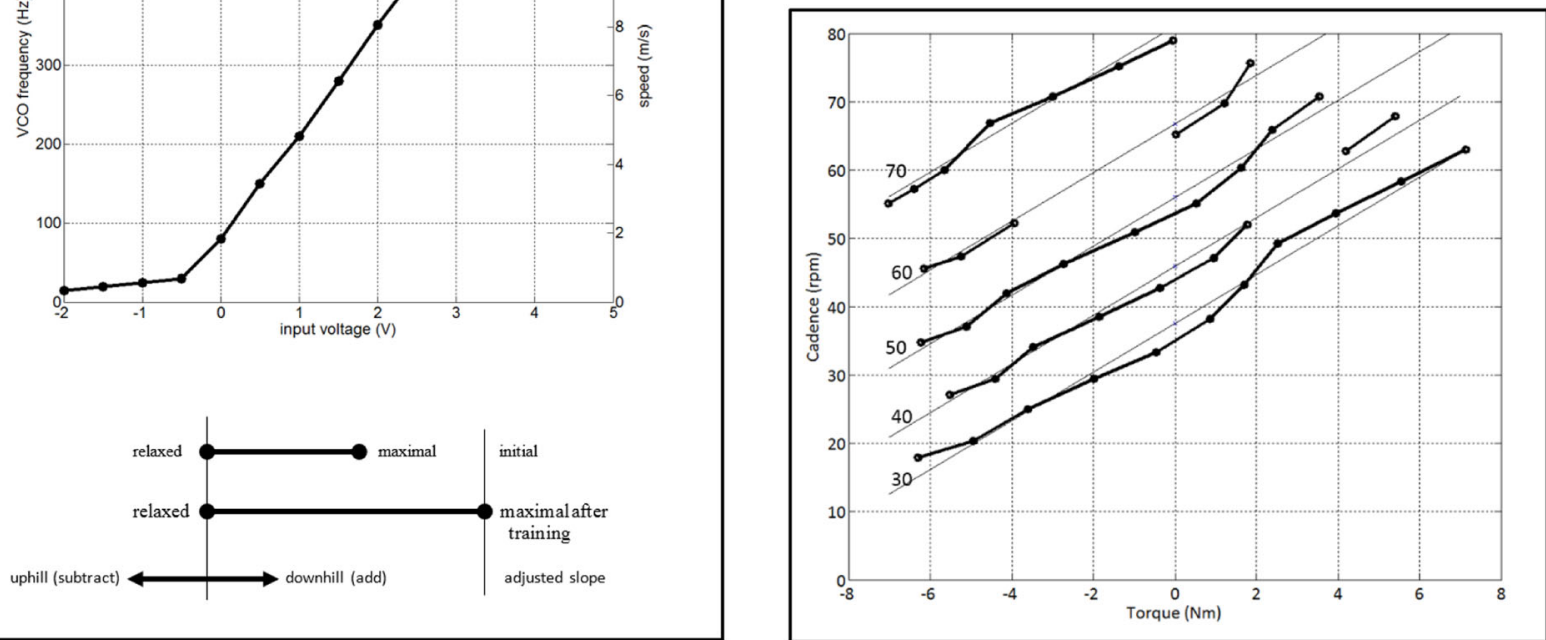

Fig. 1 a Block Diagram of iCycle. The cadence control sets the voltage applied to the DC motor. The measured torque-cadence curves are shown in (d); the stiffness was made intentionally low to avoid musculo-skeletal damage. When the torque is positive, the power supply is absorbing power which is dissipated in a heat sink. Stimulation was applied during alternate revolutions of the pedals and the output of the torque transducer is averaged over revolutions without stimulation to give the signal called effort. For each of the six stimulation channels, the output was gated so that the $30 \mathrm{~Hz}$ pulses were applied from a switch-on to a switch-off angle, which could be set for each participant. A commercial virtual reality cycling game was adapted for the iCycle. The hardware interface for this game has an output which is approximately the slope of the road in the rolling scenery. This slope is subtracted from the effort and the difference frequency-modulated by a voltagecontrolled oscillator (VCO) before being fed back as the wheelspeed. There is also a pulse signal for every revolution of the crankshaft which is switched on to start the game and synchronises the avatar's pedals with the real pedals. The VCO has an S-shaped characteristic, shown in (c), which limits the avatar's speed to $0-12 \mathrm{~m} / \mathrm{s}$. The controls labelled effort, offset and slope are used to set the working range as indicated below the graph. The feint lines in (d) are the function where $V$ is the voltage applied to the motor, $T$ is the torque (N.m) and $\Omega$ is cadence (r.p.m.). The iCycle can deliver or absorb $30 \mathrm{~W}$. $\mathbf{b}$ The iCycle is used with participants sitting in their own wheelchairs in front of the VR screen 
The iCycle is described briefly in Fig. 1. The user remains seated in their wheelchair attached by adjustable straps to the iCycle, while their feet are strapped to footplates on the cranks (see Fig. 1b). The cycling cadence is set by a motor speed control, usually while the user remains relaxed, and sometimes until spastic responses have subsided. When the game is started, the user sees an avatar cyclist moving through a rolling landscape at a speed which depends on the torque they are producing. Our aim is to design a system that can be used independently at home. Usability was therefore critical and based on our laboratory studies we measured voluntary effort via torque rather than EMG amplitudes.

The main objective of this single-group pilot study was to investigate the effects of a short-term training programme using the iCycle on ISNC-SCI motor scores after incomplete SCI. Secondary objectives were to investigate the effects of iCycle training on cycling performance as well as outcome measures for voluntary function.

\section{Methods}

The aim of this study was to measure the effects of FEScycle training combined with VR racing biofeedback on voluntary function. This study was carried out at the London Spinal Cord Injury Centre (LSCIC), Royal National Orthopaedic Hospital, Stanmore. Participants trained for three 1-h sessions per week over 4 weeks on the iCycle, which was set up in the therapy gym of the LSCIC. Outcome measures were assessed pre- and posttraining, and 4 weeks after completing training (see Fig. 2a). Ethical approval for the study was provided by the City Road and Hampstead Research Ethics Committee (13/LO/0832), and all participants gave informed written consent prior to participating in the study (Additional files 1 and 2).

\section{Participants}

Fifteen individuals with incomplete SCI (AIS B, C or D) aged 18-90 years and who were using a wheelchair for at least 2 hours per day were recruited. People were excluded if they had: a cardiac pacemaker; pressure sores or unresolved skin problems; unhealed lower limb fractures; pregnancy; active heterotrophic ossification (lower limbs); severe osteoporosis; complex regional pain syndrome; metal implants near electrode sites; lower limb malignancy; T6 and below spinal malignancy; uncontrolled autonomic dysreflexia; history of knee dislocation/subluxation; allergy to electrodes; cognitive difficulties; severe spasticity (Ashworth scale 4 or 5 in muscle groups that would prevent smooth pedalling) or neurological degenerative diseases. Participants were permitted to continue with their usual care throughout the study. Both inpatients and outpatients were recruited in order to optimise participant enrolment in the study.

\section{Outcome measures}

Outcome measures were assessed by SCI-physiotherapists at baseline (B), end of training (EOT), and follow-up (FU), 4 weeks later. Voluntary motor function was assessed using ISNC-SCI motor scores. In this paper, these motor scores are bilateral (left and right added) which is also most common in the literature. Oxford scale motor power grading was carried out for knee extension/flexion and ankle plantarflexion/dorsiflexion, and the Modified Ashworth Score (MAS) was used to assess lower limb spasticity. Participants were asked to complete the Spinal Cord Independence Measure (SCIM), and walking ability was assessed using the Walking Index for Spinal Cord Injury (WISCI II) and $10 \mathrm{~m}$-walk test.

\section{The iCycle}

The iCycle (Fig. 1) is an FES ergometer, designed specifically for people with incomplete SCI. To encourage voluntary drive during pedalling, biofeedback is used through a VR game in which the speed of the avatar depends on the actual crankshaft torque while motion is maintained by a motor. The torque is measured on alternate revolutions of the pedals when there is no stimulation to confound the measurement. The difference between the average torque, while the participant is trying to propel the pedals, and its value while they are not, but with the legs being driven by the motor, is the voluntary drive. We assume that this voluntary drive is the same during revolutions with stimulation. After experiencing stimulation on alternate revolutions, this seems reasonable, but it is only an assumption. Because the avatar's speed depends on the slope in the road, the voluntary drive must be increased if the virtual speed is to be maintained up hill. The unfolding scenery is interesting and further motivation is provided by competing (but virtual) cyclists, some of whom may be the participant in previous sessions.

\section{Setting up}

During this trial, we set up the iCycle for each participant as follows. The height of the iCycle and the distance from the wheelchair were adjusted to be comfortable and safe, ensuring no pressure or friction points on the skin. The length of the cranks was adjusted to allow a smooth cycling motion; the wheelchair was then strapped to the iCycle. The virtual route was made a velodrome. The effort gain control and the offset (Fig. 1a) were adjusted so that with the participant relaxed, the speed was very slow, while, when they made their greatest effort, the lap time was $80-100 \mathrm{~s}$. This gave 
(a)

\begin{tabular}{|c|c|c|c|}
\hline $\begin{array}{c}\text { Session } \\
\text { No. }\end{array}$ & $\begin{array}{c}\text { Week } \\
\text { No. }\end{array}$ & $\begin{array}{c}\text { Duration } \\
\text { (mins) }\end{array}$ & Description \\
\hline 1 & 1 & 180 & $\begin{array}{c}\text { OUTCOME MEASURES } \\
\text { \& SET UP WITH iCYCLE }\end{array}$ \\
\hline 2 & 1 & 35 & TRAINING \\
\hline 3 & 1 & 45 & TRAINING \\
\hline 4 & 1 & 60 & TRAINING \\
\hline 5 & 2 & 60 & TRAINING \\
\hline 6 & 2 & 60 & TRAINING \\
\hline 7 & 2 & 60 & TRAINING \\
\hline 8 & 3 & 60 & TRAINING \\
\hline 9 & 3 & 60 & TRAINING \\
\hline 10 & 3 & 60 & TRAINING \\
\hline 11 & 4 & 60 & TRAINING \\
\hline 12 & 4 & 60 & TRAINING \\
\hline 13 & 4 & 60 & TRAINING \\
\hline 14 & 4 & 120 & OUTCOME MEASURES \\
\hline 15 & 8 & 90 & OUTCOME MEASURES \\
\hline
\end{tabular}

(b)

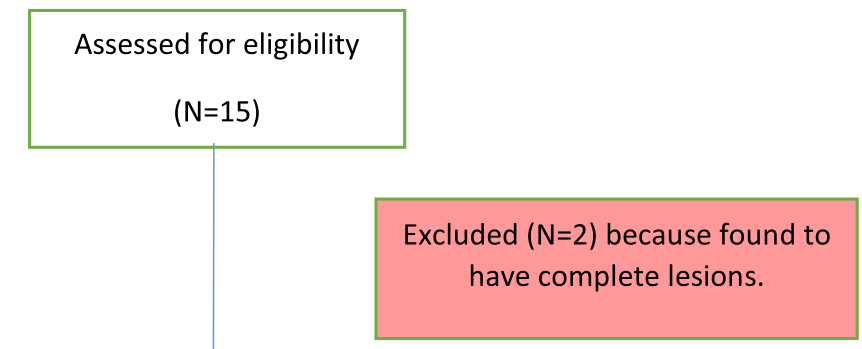

Assessed at baseline

(Session 1, N=13)

Did not complete protocol $(\mathrm{N}=2)$

because of difficulties with transport.

Assessed after treatment

(Session 14, N=11)

Assessed at Follow-up

(Session 15, N=11)

Fig. 2 a Time schedule of outcome measures and intervention (b) CONSORT flow diagram 
all participants a similar virtual speed, regardless of their ability, at the start of training. For each participant, the set-up of the iCycle (including the effort gain and offset) were documented and not adjusted after training had started.

Electrical Stimulation (ES) sectors and amplitudes were set. ES was applied to the quadriceps, hamstring and gluteal muscles bilaterally. Electrodes $(12.5 \times 7.5 \mathrm{~cm})$ were placed over the latero-proximal and medio-distal quadriceps and the proximal and distal midline of the hamstrings. Electrodes $(7 \mathrm{~cm}$ diameter $)$ were positioned proximally and distally on the midline of the gluteals. Biphasic stimulation was provided using two Odstock 4channel stimulators (Odstock Medical Ltd., UK), with rectangular pulses $200 \mu \mathrm{s}$ in width and at a frequency of $30 \mathrm{~Hz}$. During the first session, minimum (first sensation of ES) and maximum stimulation amplitudes were determined for each participant, the latter defined as the highest level tolerated or maximum muscle contraction without overflow to antagonist muscles, whichever was lower. Stimulation on/off angles were set by manually moving the pedals to each of these 12 crankshaft angles (judged by the therapist) and setting that parameter. Stimulation angles and amplitudes were documented and could be altered during training.

\section{Training}

Participants trained three times per week for 4 weeks (12 sessions in total). Total cycling time was gradually increased over the first three sessions from 20 to 30 then up to $45 \mathrm{~min}$ (depending on the participant's exercise tolerance). Each training session consisted of; (i) a warm up (passive cycling followed by cycling with ES); (ii) velodrome laps: up to 5 virtual races around the velodrome (each separated by $2-3$ min rest); (iii) free cycling: any virtual race(s) chosen by the participant and; (iv) a warm down. During the warm up, ES levels were gradually increased from each participant's minimum to maximum levels, or to the maximum intensity tolerated on that day. VR feedback was provided to the participant during each velodrome lap and during free cycling. Participants were asked to provide Rates of Perceived Exertion (RPE) at the end of each velodrome lap, and at the end of their free cycling. During free cycling, if the participant repeated a previous session's virtual race, their previous performance was displayed as a virtual competitor in the game, the aim being to provide inducement to go faster. Trainers also provided verbal encouragement throughout the velodrome laps and free cycling.

Throughout each training session, analogue signals from the iCycle (torque and shaft encoder signals) were sampled at $4 \mathrm{~Hz}$ and stored on a personal computer for offline analysis. The exact duration of cycling, the VR routes chosen, and other relevant clinical observations were recorded during each session using a training diary. Any adverse events were reported to Royal National Orthopaedic Hospital, and the chair of the Research Ethics Committee.

\section{Data management and analysis}

Each participant was given a unique ID, and data was pseudonymised at the point of collection. Participants were classified, according to time since injury at baseline, as sub-acute (<12 months post-injury) or chronic ( $>12$ months post-injury). Individual data are presented, and median, range or interquartile range (IQR), unless stated otherwise. The correlation between change in ISNC-SCI motor scores (Follow-Up minus Baseline, FUB) and other variables (age, time since injury, baseline ISNC-SCI motor score, baseline voluntary power output (PO), time spent training and stimulation amplitude) were analysed using Spearman's Rank Order Correlation (IBM SPSS statistics 25).

Data collected from the iCycle were analysed using a custom script, written in Matlab. Torque data were averaged over each revolution and separated into stimulated and non-stimulated revolutions. Cadence was calculated using the shaft encoder signal over 15-s windows. Baseline torque and cadence was calculated from a 60-s window of passive cycling during the warm up period, where there was no evidence of spasms. Torque during the nonstimulated and stimulated revolutions were calculated by subtracting the baseline torque from the measured torque signal. PO was then calculated from the torque and cadence. Improvement in PO over time was analysed using Simple Linear Regression (IBM SPSS statistics 25).

The correlation between change in voluntary PO (slope from non-stimulated revolutions) and other variables (change in ISNC-SCI motor score, age, time since injury, baseline ISNC-SCI motor score, baseline voluntary $\mathrm{PO}$, time spent training and stimulation amplitude) was analysed using Spearman's Rank Order Correlation (IBM SPSS statistics 25).

\section{Results}

Two of the 15 participants screened were not eligible and two withdrew from the study (see Fig. 2b). No data from the excluded participants was included in the analysis. Demographic details of the 11 participants who completed the study are provided in Table 1.

\section{Outcome measures}

ISNC-SCI motor scores for each participant at baseline, end-of-training and follow-up (FU) are shown in Fig. 3. The Median (IQR) improvement noted in the participants with chronic injuries $(n=6)$ was 3.5 (6.8) points; 
Table 1 Demographic data of the participants who completed the study

\begin{tabular}{|c|c|c|c|c|c|c|}
\hline Participant & Group & Gender & Age & Injury Level & AIS Grade & Time since injury \\
\hline 1 & C & $F$ & 67 & $\mathrm{T7}$ & $C$ & $11 \mathrm{y} 11 \mathrm{~m}$ \\
\hline 2 & C & M & 80 & $\mathrm{~T} 12$ & C & $3 y 5 \mathrm{~m}$ \\
\hline 4 & C & $M$ & 58 & $\mathrm{~T} 2$ & D & $6 y 8 m$ \\
\hline 5 & C & M & 55 & C1 & D & $1 \mathrm{y} 1 \mathrm{~m}$ \\
\hline 6 & C & M & 73 & $\mathrm{C} 1$ & C & $49 y$ \\
\hline 7 & C & M & 58 & $\mathrm{~T} 2$ & C & $6 y 10 m$ \\
\hline 9 & SA & M & 53 & $\mathrm{C} 3$ & C & $0 y 2 m$ \\
\hline 10 & SA & M & 67 & $\mathrm{C} 4$ & C & $0 y 4 m$ \\
\hline 12 & SA & M & 29 & $\mathrm{~T} 2$ & C & $0 y 5 m$ \\
\hline 13 & SA & $M$ & 21 & T5 & C & $0 y 3 m$ \\
\hline 15 & SA & $M$ & 61 & $\mathrm{~T} 3$ & D & $0 y 2 m$ \\
\hline
\end{tabular}

C Chronic, SA Sub-acute, AIS ASIA Impairment Scale

given their initial median ISNC-SCI motor scores were 64.0, the improvement was $10 \%$. Of these six participants with chronic injuries, two improved by 8 points or more (Fig. 3). The Median (IQR) improvement among sub-acute participants $(n=5)$ was $8.0(6.0)$ points. Initial median ISNC-SCI motor scores was 51.0, therefore the improvement was $16 \%$. Of these participants, three improved by 8 points or more, and one (\#13) improved by 19-points. Changes in ISNC-SCI motor score did not correlate with age $(\mathrm{r}=-0.51 ; p>0.05)$, time since injury $(\mathrm{r}=-0.37, p>0.05$; Fig. 4b), baseline ISNC-SCI motor score $(r=-0.02, p>0.05$; Fig. $4 c)$ or baseline PO during cycling $(r=0.02, p>0.05$; Fig. $4 d)$. Change in ISNC-SCI motor score was also uncorrelated with training stimulus (time spent training, Fig. 4e, and stimulation amplitude, Fig. 4f; $p>0.05$ for both).

Outcome measures for each participant are shown below: Oxford Scale (Table 2); MAS scores for the quadriceps, hamstrings and calf (Table 3); Total scores from the SCIM (Table 4), and a summary of these results (Table 5). Four of the five participants with sub-acute injuries, and one of the six participants with a chronic injury, had improvements in SCIM scores during training (Table 4). Only two of the participants included in the trial were ambulatory, therefore WISCI II scores and the $10 \mathrm{~m}$ walk test could only be completed for these
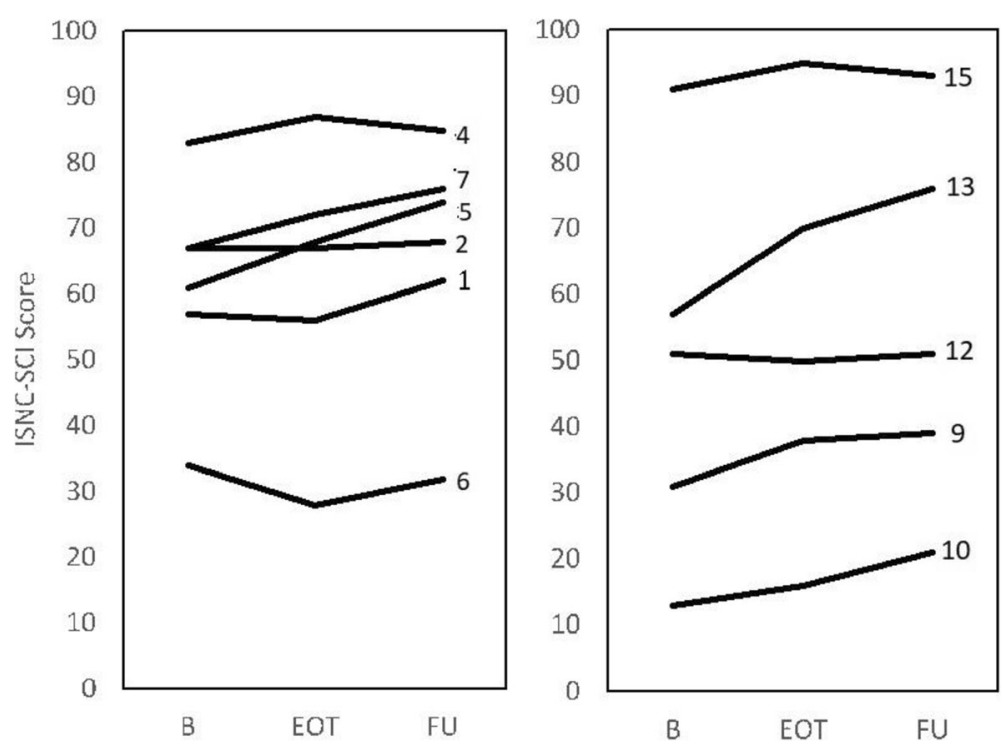

Fig. 3 Change in ISNC-SCI motor scores at baseline (B), end of training (EOT) and follow up (FU). Participant number is provided beside each data set. Participants with chronic injuries are shown in the left panel and those with sub-acute injuries are shown on the right. The graph shows the changes on a scale from 0 (complete paralysis) to 100 (able-bodied) 

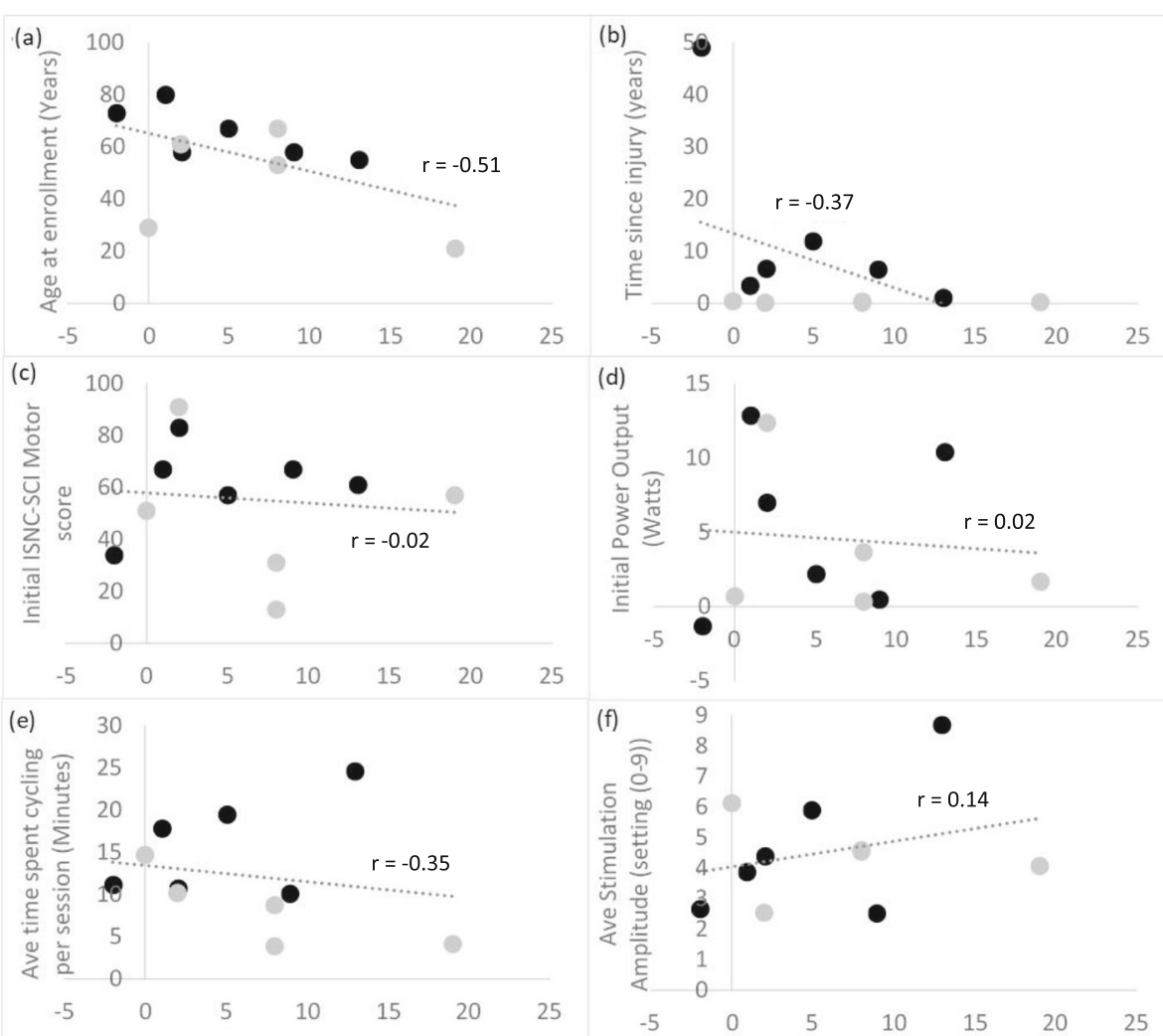

Change in ISNC-SCI Motor Score (EOT-B)

Fig. 4 Change in ISNC-SCI motor scores at follow up (FU) relative to baseline (B), plotted against (a) age (years) at time of enrolment to the study, (b) time since injury (years), (c) initial ISNC-SCI score, (d) initial power output (watts), (e) cycling duration per session (min), (f) average stimulation amplitude (stimulator setting). Participants with chronic injuries are shown in black, those with sub-acute injuries in grey

participants (\#7 and \#15). Participant \#7 showed no change in either measure, whereas Participant \#15 demonstrated an improvement in WISCI II score of 5 points at EOT compared with Baseline, and $10 \mathrm{~m}$ walk test time improved from $82 \mathrm{~s}$ at baseline to $41 \mathrm{~s}$ at EOT.

\section{Training}

All 11 participants completed 12 training sessions, with no reported serious adverse events. An example raw torque trace taken from the iCycle after a single session is provided in Fig. 5 (upper panel), indicating baseline, three velodrome laps and one cross-country route completed by the participant. Average stimulation amplitude used by each participant on each muscle group across all training sessions is provided in Table 6. Average Rates of Perceived Exertion (RPE) for each participant across all sessions is also provided in Table 6.

In 4 participants (\#1, \#6, \#7 and \#13), voluntary effort caused negative torque, as shown in Fig. 5 (lower panel), presumably due to spasticity. Negative torque was associated with voluntary intent to cycle rather than passive cycling, or FES cycling, since the torque was more negative during each velodrome lap and the cross-country route compared with passive cycling (baseline) and FES cycling (FES was provided throughout the session after baseline data had been collected).

\section{Velodrome laps}

Each participant completed up to five virtual laps of the velodrome at the start of each training session (typically three were completed per session). Each of these laps was timed, and lap times were intended to provide session-to-session feedback to the participants. For each session, average PO during the fastest velodrome lap (from both the stimulated and non-stimulated revolutions) was calculated (Fig. 6). Some participants showed increases in PO with training whereas other did not. From the regression lines (Fig. 6), participants 2, 4 and 9 had a moderate improvement in $\mathrm{PO}$ with training $\left(\mathrm{R}^{2}>\right.$ 0.3 ), and participants 5 and 15 showed a greater improvement in $\mathrm{PO}$ with training $\left(\mathrm{R}^{2}>0.7\right)$. The remaining subjects showed little or no change. Improvement in PO 
Table 2 Oxford scale motor power charting for all participants at Baseline, End-of-Training (EOT) and Follow-Up (FU) for lower limb muscles

\begin{tabular}{|c|c|c|c|c|c|c|c|c|c|c|c|c|c|}
\hline \multicolumn{2}{|c|}{ Participant } & \multicolumn{6}{|c|}{ Flexion/Dorsiflexion } & \multicolumn{6}{|c|}{ Extension/Plantarflexion } \\
\hline & & \multicolumn{3}{|c|}{ Right } & \multicolumn{3}{|c|}{ Left } & \multicolumn{3}{|c|}{ Right } & \multicolumn{3}{|c|}{ Left } \\
\hline & & B & EOT & $\mathrm{FU}$ & B & EOT & $\overline{F U}$ & $B$ & EOT & $\overline{F U}$ & $B$ & EOT & FU \\
\hline \multirow[t]{2}{*}{1} & Knee & 0 & 0 & 0 & 0 & 0 & 0 & 1 & 1 & 1 & 0 & 0 & 2 \\
\hline & Ankle & 0 & 0 & 0 & 2 & 2 & 2 & 1 & 0 & 1 & 1 & 1 & 2 \\
\hline \multirow[t]{2}{*}{2} & Knee & 1 & 2 & 2 & 2 & 2 & 2 & 5 & 5 & 5 & 2 & 2 & 3 \\
\hline & Ankle & 0 & 0 & 0 & 0 & 0 & 0 & 1 & 0 & 1 & 1 & 0 & 0 \\
\hline \multirow[t]{2}{*}{4} & Knee & 1 & 1 & 1 & 3 & 3 & 3 & 2 & 4 & 3 & 2 & 4 & 4 \\
\hline & Ankle & 2 & 3 & 1 & 4 & 4 & 5 & 4 & 4 & 4 & 4 & 4 & 5 \\
\hline \multirow[t]{2}{*}{5} & Knee & 1 & 4 & 4 & 2 & 1 & 2 & 2 & 3 & 3 & 1 & 2 & 2 \\
\hline & Ankle & 2 & 4 & 3 & 1 & 1 & 1 & 2 & 4 & 5 & 2 & 2 & 3 \\
\hline \multirow[t]{2}{*}{6} & Knee & 0 & 0 & 0 & 0 & 0 & 0 & 1 & 1 & 1 & 1 & 0 & 1 \\
\hline & Ankle & 1 & 0 & 0 & 0 & 0 & 0 & 1 & 0 & 0 & 0 & 0 & 0 \\
\hline \multirow[t]{2}{*}{7} & Knee & 1 & 1 & 2 & 0 & 1 & 1 & 2 & 3 & 3 & 2 & 2 & 3 \\
\hline & Ankle & 3 & 3 & 3 & 1 & 3 & 3 & 2 & 3 & 3 & 1 & 1 & 3 \\
\hline \multirow[t]{2}{*}{9} & Knee & 1 & 2 & 2 & 2 & 3 & 3 & 1 & 1 & 2 & 3 & 3 & 4 \\
\hline & Ankle & 1 & 2 & 2 & 3 & 4 & 4 & 1 & 2 & 2 & 3 & 5 & 4 \\
\hline \multirow[t]{2}{*}{10} & Knee & 0 & 1 & 0 & 0 & 1 & 1 & 0 & 1 & 1 & 0 & 1 & 2 \\
\hline & Ankle & 0 & 0 & 0 & 0 & 1 & 2 & 0 & 1 & 2 & 0 & 2 & 3 \\
\hline \multirow[t]{2}{*}{12} & Knee & 0 & 0 & 0 & 0 & 1 & 0 & 0 & 0 & 0 & 1 & 0 & 0 \\
\hline & Ankle & 0 & 0 & 0 & 0 & 0 & 0 & 0 & 0 & 0 & 0 & 0 & 0 \\
\hline \multirow[t]{2}{*}{13} & Knee & 1 & 1 & 1 & 2 & 1 & 1 & 2 & 3 & 3 & 3 & 4 & 4 \\
\hline & Ankle & 2 & 2 & 3 & 3 & 3 & 4 & 2 & 1 & 1 & 2 & 1 & 1 \\
\hline \multirow[t]{2}{*}{15} & Knee & 4 & 4 & 4 & 2 & 3 & 3 & 5 & 5 & 5 & 2 & 4 & 4 \\
\hline & Ankle & 4 & 5 & 5 & 5 & 5 & 5 & 4 & 5 & 5 & 3 & 4 & 4 \\
\hline
\end{tabular}

Table 4 Spinal Cord Independence Measure (SCIM) scores for all participants at Baseline, End-of-Training (EOT) and Follow-Up (FU) (data provided are summed across sub categories).

Participants whose SCIM score changed during the study are shaded

\begin{tabular}{|c|c|c|c|}
\hline \multirow[t]{2}{*}{ Participant } & \multicolumn{3}{|c|}{ SCIM } \\
\hline & $B$ & EOT & FU \\
\hline 1 & 67 & 67 & 67 \\
\hline 2 & 68 & 68 & 68 \\
\hline 4 & 74 & 74 & 74 \\
\hline 5 & 43 & 44 & 45 \\
\hline 6 & 54 & 54 & 54 \\
\hline 7 & 69 & 69 & 69 \\
\hline 9 & 19 & 20 & 20 \\
\hline 10 & 10 & 11 & 16 \\
\hline 12 & 71 & 71 & 71 \\
\hline 13 & 74 & 75 & 77 \\
\hline 15 & 70 & 83 & 83 \\
\hline
\end{tabular}

did not correlate with change in ISNC-SCI motor score $(\mathrm{r}=0.01, p>0.05$, Fig. 7a), but was related to their baseline cycling ability shown by a significant, positive correlation between slope and baseline PO $(r=0.71, p=$ 0.02, Fig. 7b).

\section{Free cycling}

Average time spent free cycling during each session ranged from 4 to 25 mins. There was no correlation between time spent cycling and change in $\mathrm{PO}$ with training $(\mathrm{r}=0.03, p>0.05$, Fig. $7 \mathrm{c}$ ). Comments noted in the training diaries (by physiotherapists) included the occurrence of spasms during the session $(n=18)$, and participants' anecdotal statements, as follows: enjoyment/pleased with

Table 3 Modified Ashworth Score (MAS) to assess lower limb spasticity at Baseline, End-of-Training (EOT) and Follow-Up (FU)

\begin{tabular}{|c|c|c|c|c|c|c|c|c|c|c|c|c|c|c|c|c|c|c|}
\hline \multirow[t]{3}{*}{ Participant } & \multicolumn{6}{|c|}{ Quadriceps } & \multicolumn{6}{|c|}{ Hamstrings } & \multicolumn{6}{|c|}{ Calf } \\
\hline & \multicolumn{3}{|c|}{ Right } & \multicolumn{3}{|c|}{ Left } & \multicolumn{3}{|c|}{ Right } & \multicolumn{3}{|c|}{ Left } & \multicolumn{3}{|c|}{ Right } & \multicolumn{3}{|c|}{ Left } \\
\hline & $B$ & EOT & $\mathrm{FU}$ & $B$ & EOT & FU & $B$ & EOT & $\mathrm{FU}$ & $B$ & EOT & $\mathrm{FU}$ & $B$ & EOT & $\mathrm{FU}$ & $B$ & EOT & $\mathrm{FU}$ \\
\hline 1 & 2 & 0 & 0 & 2 & 0 & 0 & 1 & 1 & 1 & 1 & 1 & 1 & 2 & 0 & 1 & 1 & 1 & 1 \\
\hline 2 & 0 & 0 & 0 & 0 & 0 & 0 & 0 & 0 & 0 & 0 & 0 & 0 & 0 & 0 & 0 & 0 & 0 & 0 \\
\hline 4 & 3 & 2 & 3 & 3 & 1 & 2 & 3 & 2 & 3 & 3 & 1 & 2 & 3 & 2 & 3 & 3 & 1 & 2 \\
\hline 5 & 4 & 3 & 3 & 4 & 4 & 4 & 4 & 3 & 3 & 4 & 4 & 5 & 4 & 4 & 3 & 5 & 5 & 4 \\
\hline 6 & 3 & 4 & 3 & 4 & 3 & 3 & 3 & 3 & 3 & 4 & 3 & 3 & 3 & 3 & 3 & 3 & 3 & 3 \\
\hline 7 & 1 & 1 & 1 & 2 & 1 & 1 & 1 & 1 & 1 & 2 & 1 & 1 & 2 & 1 & 1 & 3 & 1 & 1 \\
\hline 9 & 2 & 2 & 3 & 1 & 1 & 2 & 2 & 2 & 3 & 1 & 1 & 2 & 2 & 2 & 3 & 1 & 1 & 2 \\
\hline 10 & 2 & 2 & 1 & 3 & 2 & 1 & 2 & 2 & 1 & 3 & 0 & 1 & 2 & 1 & 1 & 3 & 0 & 1 \\
\hline 12 & 2 & 3 & 3 & 1 & 2 & 2 & 1 & 2 & 1 & 1 & 1 & 1 & 1 & 2 & 2 & 1 & 2 & 2 \\
\hline 13 & 0 & 1 & 1 & 0 & 1 & 1 & 0 & 3 & 3 & 0 & 3 & 2 & 1 & 3 & 1 & 1 & 3 & 1 \\
\hline 15 & 1 & 0 & 0 & 2 & 0 & 1 & 1 & 0 & 0 & 1 & 2 & 2 & 2 & 0 & 0 & 2 & 2 & 2 \\
\hline
\end{tabular}


Table 5 Summary of collected results for the outcome measures

\begin{tabular}{|c|c|c|c|c|c|}
\hline \multirow[t]{2}{*}{ Test } & \multirow[t]{2}{*}{ Measure of } & \multirow[t]{2}{*}{ Scale } & \multicolumn{3}{|c|}{$\begin{array}{l}\text { Change from Baseline to Follow-up } \\
\text { (all participants) }\end{array}$} \\
\hline & & & & Median & Range \\
\hline ISNC-SCI & SCl Classification & $0-100$ & & 5.0 & $-2.0--+19.0$ \\
\hline \multirow[t]{4}{*}{ Oxford } & \multirow[t]{4}{*}{ Strength } & \multirow[t]{4}{*}{$0-5$} & Knee Flex & 0.5 & $-1.0--+3.0$ \\
\hline & & & Knee Ext & 1.0 & $-1.0--+2.0$ \\
\hline & & & Ankle DF & 0.5 & $-1.0--+2.0$ \\
\hline & & & Ankle PF & 0.5 & $-1.0--+3.0$ \\
\hline SCIM & Independence: mobility & $0-80$ & & 0.0 & $0.0--+13.0$ \\
\hline \multirow[t]{3}{*}{ Ashworth (MAS) } & \multirow[t]{3}{*}{ Severity of spasticity } & \multirow[t]{3}{*}{$0-4$} & Quads & -0.5 & $-2.0--+1.0$ \\
\hline & & & Hams & 0.0 & $-1.0--+3.0$ \\
\hline & & & Calf & -0.5 & $-2.0--+1.0$ \\
\hline
\end{tabular}

the iCycle session $(n=5)$, improved standing when using a standing frame $(\mathrm{n}=5)$, improved sleeping/sleeping well $(n=4)$, improved sensation $(n=4)$, increased alertness $(\mathrm{n}=1)$, increased thigh size $(\mathrm{n}=1)$ and improved ability to flex hip $(\mathrm{n}=1)$. Two participants noticed skin redness at the end of a session, these were reported as adverse events.

\section{Discussion}

This trial explored the effects of a 4-week, 12-session training programme using a novel FES bike, the iCycle, which used VR biofeedback to encourage voluntary effort. Improvements in ISNC-SCI motor scores were noted in both chronic and sub-acute participants (improvements $\geq 8$ points in 5 out of the 11 participants); these improvements were unrelated to all other measured variables (Fig. 4). Moderate improvements in cycling $\mathrm{PO}$ were noted with training, but these were unrelated to improvements in ISNC-SCI motor scores: while some participants showed improvements in both PO and motor scores (e.g. \#5), others showed considerable increases in ISNC-SCI motor score without any improvement in cycling PO (e.g. \#7 and \#13). Overall the results were variable, as shown by Table 5 .

Among sub-acute participants, median improvement in ISNC-SCI motor score was 8.0 points (16\% from B to FU), with 4 out of the 5 participants showing improvements. All of our sub-acute participants were between 2 and 5 months post-injury when enrolling in the study. The majority of natural recovery is known to occur during the first 6 months post injury [22-24]: Geissler et al [23] collected data from over 700 patients and showed

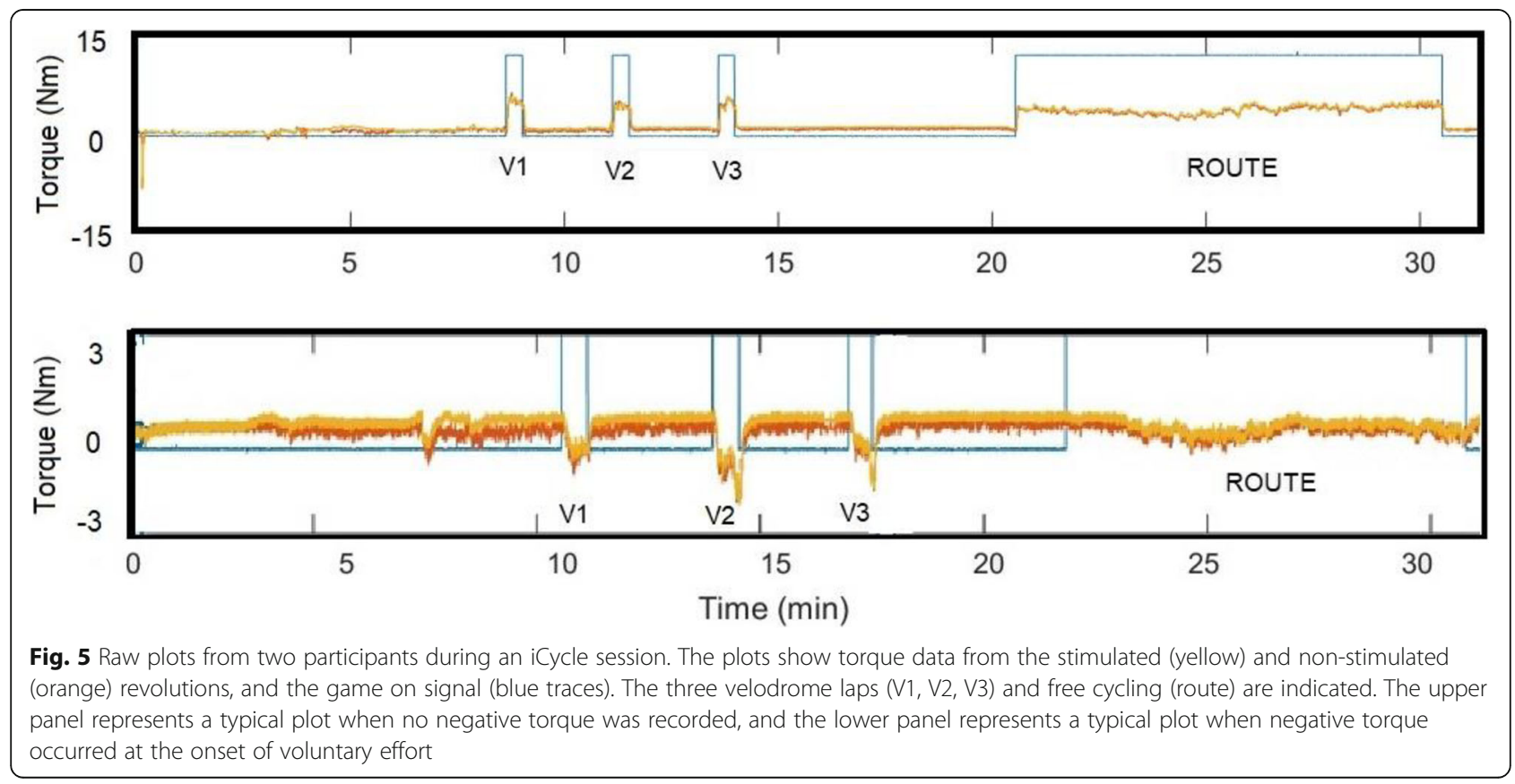


Table 6 Average (SD) stimulation amplitude for quadriceps, hamstrings and gluteals, and Rates of Perceived Exertion (RPE) for each participant across all training sessions

\begin{tabular}{|c|c|c|c|c|c|}
\hline \multirow[t]{2}{*}{ Participant } & \multicolumn{3}{|c|}{ Stimulation Amplitude } & \multicolumn{2}{|c|}{ Rates of Perceived Exertion (RPE) } \\
\hline & Quadriceps & Hamstrings & Gluteals & Laps & Free cycling \\
\hline 1 & $5.0(1.4)$ & $7.5(0.6)$ & $4.1(0.2)$ & $13.0(0.4)$ & $12.6(1.4)$ \\
\hline 2 & $3.3(0.6)$ & $3.9(1.1)$ & $4.8(1.0)$ & $14.3(0.9)$ & $14.6(1.8)$ \\
\hline 4 & $4.3(0.6)$ & $4.1(0.3)$ & $4.7(0.5)$ & $16.1(1.1)$ & $16.5(0.8)$ \\
\hline 5 & $8.7(0.6)$ & $8.8(0.4)$ & $8.6(0.6)$ & $13.4(0.8)$ & $14.5(1.2)$ \\
\hline 6 & $2.9(0.4)$ & $2.5(0.3)$ & $2.5(0.3)$ & $12.2(0.8)$ & $14.2(0.6)$ \\
\hline 7 & $2.4(0.4)$ & $2.7(0.4)$ & $0.0(0.0)$ & $11.6(0.6)$ & $13.3(0.5)$ \\
\hline 9 & $4.9(0.5)$ & $5.4(0.9)$ & $3.4(0.6)$ & $12.3(0.4)$ & $12.5(0.5)$ \\
\hline 10 & $5.3(1.0)$ & $4.7(0.8)$ & $3.8(0.7)$ & $13.0(0.5)$ & $13.3(0.8)$ \\
\hline 12 & $5.9(1.6)$ & $5.4(1.4)$ & $7.4(1.0)$ & $9.5(0.6)$ & $13.3(0.8)$ \\
\hline 13 & $3.6(1.2)$ & $3.8(1.2)$ & $4.8(1.7)$ & $11.2(0.8)$ & $13.2(0.9)$ \\
\hline 15 & $2.9(0.3)$ & $2.3(0.5)$ & $2.5(0.4)$ & $13.5(0.9)$ & $16.1(1.4)$ \\
\hline
\end{tabular}

Stimulation amplitude is provided on an arbitrary scale (0-9), which represents $0-115 \mathrm{~mA}$ into a $1 \mathrm{k}$ ohm load.

changes of about 35 points for cervical and thoracic C \& $\mathrm{D}$ patients in the 52 weeks after injury, nearly all in the first 26 weeks. It is therefore not possible to distinguish the effect of natural recovery from neurological recovery due to iCycle training in the first year. However, the improvements we noted occurred over a relatively short period ( 8 weeks), therefore a large RCT is warranted to verify whether iCycle training increases natural recovery rate in sub-acute participants. Functional improvement was noted in SCIM scores, from 8 at B to 13 at EOT and retained at FU (Table 4), and walking in the only ambulatory sub-acute participant [15] improved from walking with a frame and one person to assist, to a frame without assistance.

Among the participants with chronic injuries, median improvement in ISNC-SCI motor score was 3.5 points (10\% from B to FU). Yaşar et al. [14] tested FES cycling without voluntary effort (participants were told not to contribute voluntarily to the cycling) in ten people with chronic AIS C \& D injuries and found similar median improvement in motor score (3.0 points) but after 3 months training as opposed to 1 month in our study. Therefore, using feedback on voluntary effort in our study may have increased the rate at which changes occurred. Our findings can also be compared to motor recovery seen after gait training for AIS C \& D people. Morrison et al. [25] reported ISNC-SCI scores from 60 participants (0.1-45 years post injury) doing 120 sessions of body-weight supported locomotor training. The training time averaged (SD) 11.3 (9.3) months (sessions every 3 days) and the mean improvement in lower-limb motor scores was 6 , suggesting that recovery rate (as assessed by ISNC-SCI) is slower with gait training than iCycle training. Recently, Wagner et al. [26] reported greater motor recovery on 3 participants with chronic incomplete SCI (AIS C \& D) who carried out overground walking training combined with epidural stimulation for 5 months (the number of training sessions was not stated). At the end, their motor scores increased by 16,11 and 4 respectively (mean 10.3).

Among chronic participants, motor recovery can be assumed to be related to the intervention, although the placebo effect of taking part in a research study should not be discounted. Improvements in motor function of 8 points or higher (as noted in Participants \#5 and \#7) indicated clinically important gains in neurological and muscle function [27-29]. Other functional improvements were also noted in these participants: 2-point increase in SCIM score (\#5) and anecdotal report of improved standing when using a frame (\#7).

Improvements in ISNC-SCI motor score appeared to be unrelated to age, but the two chronic participants who experienced little or no improvement in motor scores (participants \#2 and \#6) were the oldest (both > 70 years); in these participants recovery may have been limited by atrophy of the musculoskeletal system known to occur with aging [30]. Improvements in ISNC-SCI motor score also appeared to be unrelated to injury classification or time since injury (Fig. 4b-d). However, there may be injury-related factors that are not captured by the ISNC-SCI scoring system that explain why some participants appeared to respond to the intervention where others did not, such as the presence of nonfunctional residual pathways crossing the lesion site.

Our original idea was that neuroplasticity would be enhanced by temporal correlation of voluntary effort and electrical stimulation of the paralysed or paretic muscles, based on Hebbian learning. This hypothesis is not supported by the poor correlation between stimulation intensity and improvement in ISNC-SCI (Fig. 4f). 


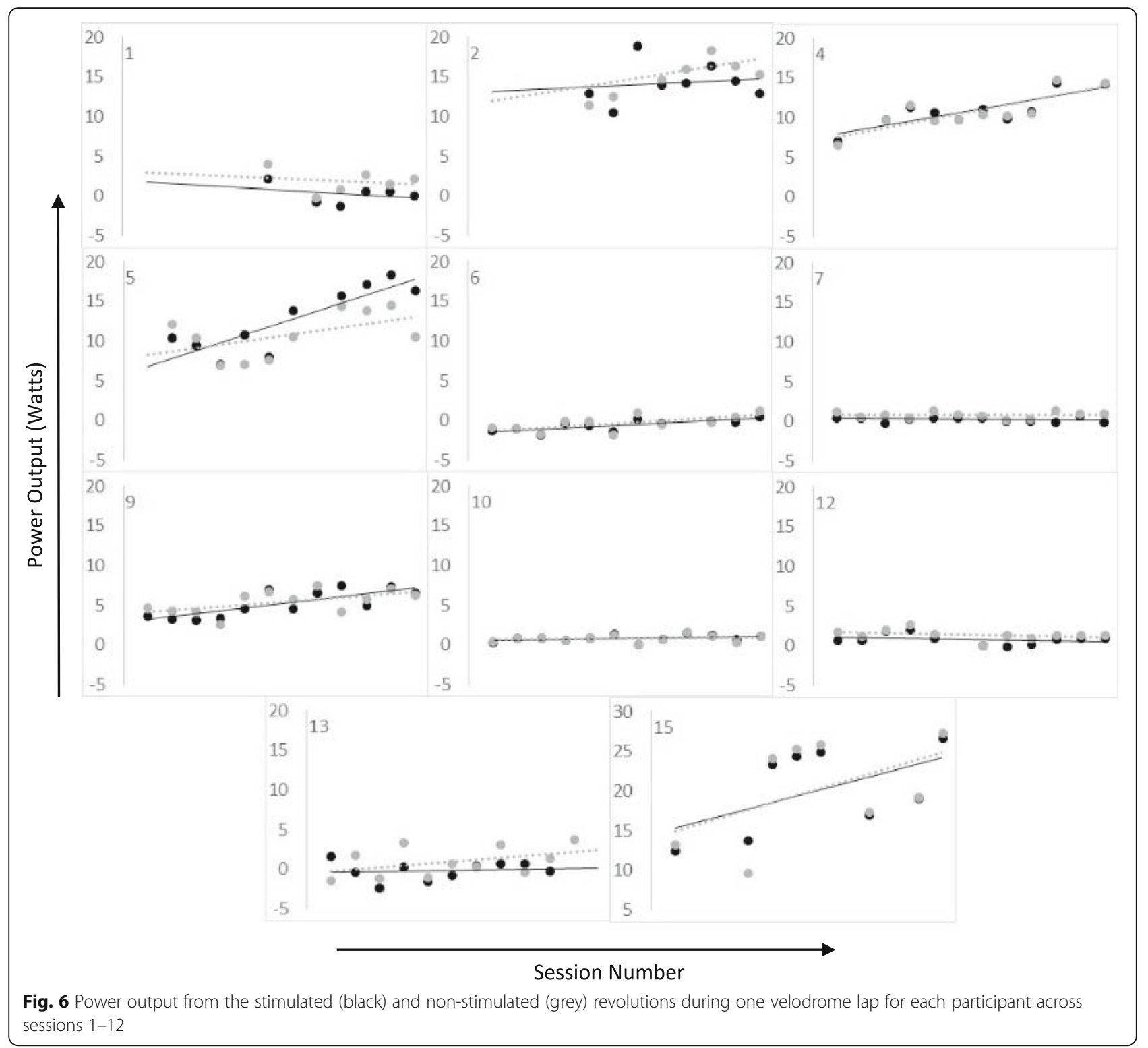

FES is different from the more general "activity-based restoration" advocated by Sadowsky \& McDonald [31]. It is of great practical importance to know what the relative contributions to recovery are from muscle stimulation, from motor-driven leg motion, and from voluntary effort.

\section{Cycling performance}

In some subjects moderate increases in peak cycling PO were noted at EOT compared to B (up to a maximum of $14 \mathrm{~W}$, see Fig. 6). These are similar to the relatively small improvements that have been reported previously after FES cycle training [6], which are attributable to observed improvements in lower limb muscle size [13, 32-34] and strength $[6,13,32]$. We observed a moderate correlation $\left(R^{2}=0.64\right.$, Fig. $\left.7 b\right)$ between baseline PO (from the non- stimulated revolutions) and the change in PO with training, indicating that the subjects with higher voluntary power at baseline were more likely to improve with training.

The average PO measured over a single velodrome lap was somewhat variable across sessions, ranging from $-1.9 \mathrm{~W}$ to $+27.3 \mathrm{~W}$ during stimulated revolutions and $-2.3 \mathrm{~W}$ to $+26.6 \mathrm{~W}$ during non-stimulated revolutions. Previous FES cycling studies report POs of similar magnitude (0-35 W [35]), however, the majority of previous work has been in people with complete injuries, which usually allows for high stimulation currents $(\sim 60-100 \mathrm{~mA}$ is typically used). Our participants had variable sensory impairments, which restricted stimulation current levels. The additional FES had little impact on PO, perhaps due to the rapid fatigue caused by FES [35]. 

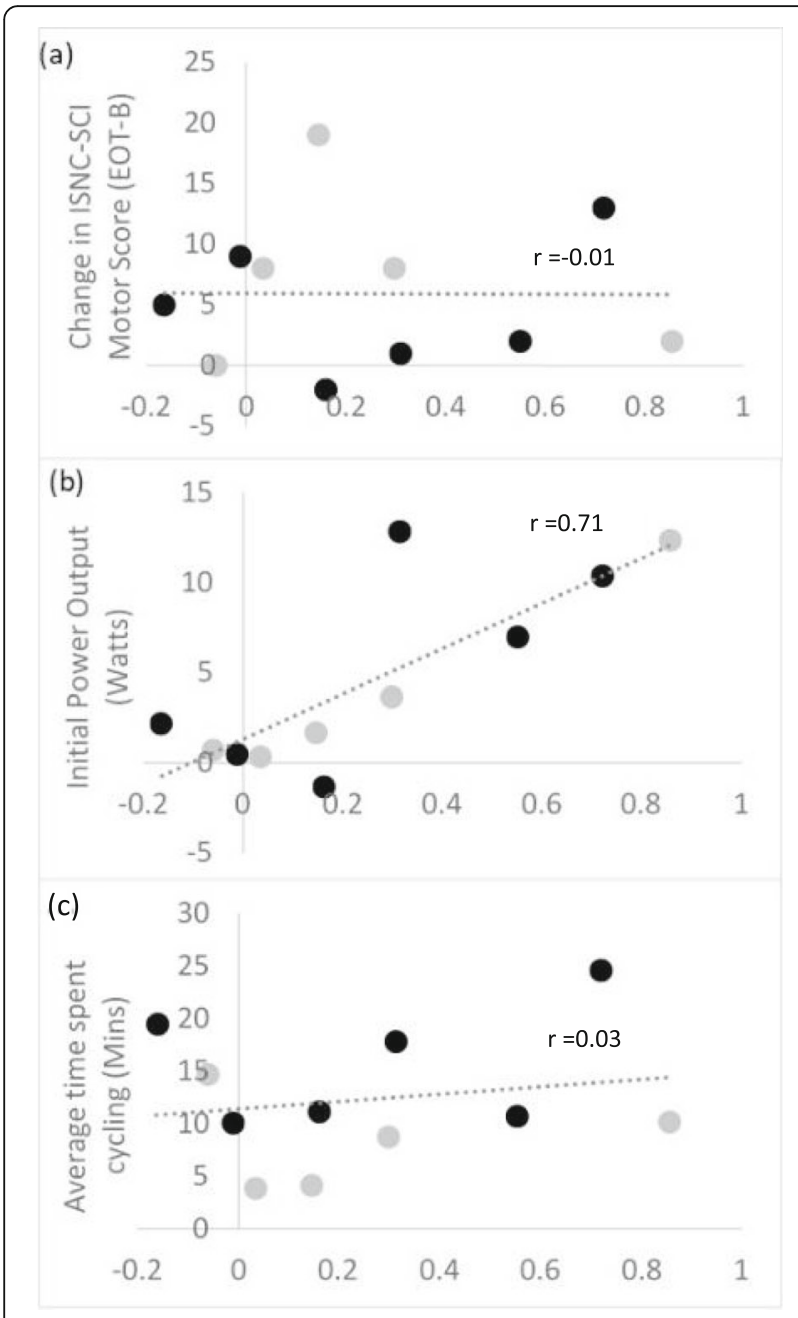

Change in Power Output (Regression Slope)

Fig. 7 Change in power output (regression slopes taken from Fig. 6) plotted against (a) initial ISNC-SCI score, (b) initial power output (watts), (c) cycling duration per session (min). Participants with chronic injuries are shown in black, those with sub-acute injuries in grey

Negative POs during training (FES combined with voluntary effort, see Fig. 5, lower panel) were an unexpected finding: negative torque was not due to passive resistance (e.g. weight of the limbs) as this had been corrected for. The negative $\mathrm{PO}$ was principally due to co-contraction of lower limb muscles at the start of the VR game (FES had already been switched on at this point), perhaps due to spasms. This was additionally documented by physiotherapists in the training diaries. Presumably, FES combined with voluntary effort facilitated central nervous system excitability [36], which may have provoked antagonistic co-contraction, due to impaired reciprocal inhibition in people with incomplete SCI $[37,38]$. For example, during active pedalling, normal modulation of the soleus $\mathrm{H}$-reflex has been reported to be reduced or absent in people with incomplete
SCI due to loss of supraspinal control over inhibitory spinal mechanisms [37].

The commercially available software used for training offered many different VR environments, including mountainous or flat terrain. During training, participants were able to view their previous performance by means of a virtual competitor in the software programme, and reported that this was particularly motivating. Time spent cycling in different VR environments varied across participants, ranging from approximately $5-25 \mathrm{~min}$. There was no correlation between training duration and improvements in ISNC-SCI motor scores, or PO during cycling.

\section{Limitations \& future work}

This was a small pilot study of a novel device, which did not include a control group. The study has identified where technical improvements are needed, and informed choice of outcome measures. The use of PO alone as a measure of recovery is unsatisfactory because it may be confounded by muscle-training effects. In future, functional outcome measures should be combined with measures that provide insight into underlying neuroplastic mechanisms such as motor-evoked potentials to assess changes in the motor pathway. Results were variable and larger, better-controlled clinical trials are needed to prove that the addition of VR biofeedback increases the rate of recovery from FES cycling. The dose of cycling was not equal for all participants, either in minutes or pedal revolutions; this could be changed in future if this restriction on the participants was considered important. From a clinical perspective, the aim of rehabilitation is to challenge patients to extend their ability. As each patient has a different ability level, to be optimised clinically, both time and pedal revolutions need to be variable both within and between patients. The long-term objective of the work is to develop a device and protocol that are clinically useful, rather than to perform a purely scientific experiment.

There were some limitations of the iCycle, which we propose to address before conducting further clinical trials. Some arrangement is required so that participants who produce negative torques are not disincentivised. We found that weak participants produced torques that were too small compared to the background interference: this may be improved by better filtering of the torque signal, or perhaps by using EMG during the nonstimulated revolutions. The biofeedback system may also be improved by optimising the VR environment, for example by introducing remote virtual races and/or creating a more immersive VR environment. The participants in this study were particularly encouraged by racing against their previous performance, displayed as a virtual competitor, therefore introducing a multi-player 
environment where participants are able to compete against other SCI participants within a virtual race might also provide an effective stimulus to encourage voluntary effort and participation.

\section{Conclusions}

The iCycle is an innovative progression of traditional FES cycling systems: it provides VR biofeedback based only on the voluntarily generated torque to encourage voluntary effort. Following a 4-week intervention using the iCycle, improvements in ISNC-SCI motor scores were noted in both chronic and sub-acute participants (improvements $\geq 8$ points in 5 out of the 11 participants). Our data suggest that recovery rate may be faster when voluntary effort is combined with FES cycling with VR biofeedback. Larger controlled trials are needed to verify these findings and to understand the mechanisms of effect.

\section{Supplementary information}

Supplementary information accompanies this paper at https://doi.org/10. 1186/s12984-019-0619-4

Additional file 1. Participant Information Sheet.

Additional file 2. Consent Form.

\section{Abbreviations}

AIS: ASIA Impairment Scale; B: Baseline; EOT: End of Training; FES: Functional Electrical Stimulation; FU: Follow up; ISNC-SCI: International Standards for Neurological Classification of Spinal Cord Injury; LSCIC: London Spinal Cord Injury Centre; MAS: Modified Ashworth Scale; PO: Power Output; SCI: Spinal Cord Injury; SCIM: Spinal Cord Independence Measure; SD: Standard Deviation; TMS: Transcranial Magnetic Stimulation; VR: Virtual Reality; WISCI II: Walking Index for Spinal Cord Injury |I

\section{Acknowledgements}

The authors gratefully acknowledge Emma Cook, Sandra Bulpitt and Laura Bochkoltz for assistance during training sessions. We also wish to express our sincere thanks to the study participants.

\section{Authors' contributions}

LD contributed to acquiring data, analysed and interpreted the patient data regarding the iCycle, drafted and revised the manuscript; SP contributed to study design, substantially contributed to data acquisition and critically revised the manuscript; AA substantially contributed to study design and data acquisition and critically revised the manuscript; ND contributed substantially to study conception and iCycle design, provided engineering support for data collection, and critically revised the manuscript; JB contributed substantially to study conception and design, analysed and interpreted the clinical patient data, contributed to drafting the manuscript and revised it critically. All authors read and approved the final manuscript.

\section{Funding}

This study was funded by the Inspire Foundation.

\section{Availability of data and materials}

The datasets used and/or analysed during the current study are available from the corresponding author on reasonable request.

\section{Ethics approval and consent to participate}

Ethical approval for the study was provided by the City Road and Hampstead Research Ethics Committee (13/LO/0832), and all participants gave informed written consent prior to participating in the study (see Additional files 1 and 2).

\section{Consent for publication}

NA

\section{Competing interests}

The authors declare that they have no competing interests.

\section{Author details}

${ }^{1}$ Department of Medical Physics \& Biomedical Engineering, University College London, Malet Place Engineering Building, Gower Street, London WC1E 6BT, UK. ${ }^{2}$ London Spinal Cord Injury Centre, Royal National Orthopaedic Hospital, Stanmore, UK. ${ }^{3}$ Faculty of Environmental and Life Sciences, University of Southampton, Southampton, UK

Received: 13 March 2019 Accepted: 6 November 2019

Published online: 27 November 2019

\section{References}

1. Levin MF, Kleim JA, Wolf SL. What do motor "recovery" and "compensation" mean in patients following stroke? Neurorehabil Neural Repair. 2009;23(4): 313-9.

2. Harness ET, Yozbatiran N, Cramer SC. Effects of intense exercise in chronic spinal cord injury. Spinal Cord. 2008;46(11):733-7.

3. Dobkin B, Apple D, Barbeau H, Basso M, Behrman A, Deforge D, et al, Weight-supported treadmill vs over-ground training for walking after acute incomplete SCI. Neurology. 2006;66(4):484-93.

4. Remple MS, Bruneau RM, VandenBerg PM, Goertzen C, Kleim JA. Sensitivity of cortical movement representations to motor experience: evidence that skill learning but not strength training induces cortical reorganization. Behav Brain Res. 2001;123(2):133-41.

5. Edgerton VR, Roy RR. Robotic training and spinal cord plasticity. Brain Res Bull. 2009;78(1):4-12

6. Duffell LD, Donaldson NN, Perkins TA, Rushton DN, Hunt KJ, Kakebeeke TH, et al. Long-term intensive electrically stimulated cycling by spinal cordinjured people: effect on muscle properties and their relation to power output. Muscle Nerve. 2008;38(4):1304-11.

7. Taylor PN, Burridge JH, Dunkerley AL, Wood DE, Norton JA, Singleton C, et al. Clinical use of the Odstock dropped foot stimulator: its effect on the speed and effort of walking. Arch Phys Med Rehabil. 1999;80(12):1577-83.

8. Field-Fote EC. Combined use of body weight support, functional electric stimulation, and treadmill training to improve walking ability in individuals with chronic incomplete spinal cord injury. Arch Phys Med Rehabil. 2001; 82(6):818-24.

9. Barbeau H, Ladouceur M, Mirbagheri MM, Kearney RE. The effect of locomotor training combined with functional electrical stimulation in chronic spinal cord injured subjects: walking and reflex studies. Brain Res Brain Res Rev. 2002:40(1-3):274-91.

10. Postans NJ, Hasler JP, Granat MH, Maxwell DJ. Functional electric stimulation to augment partial weight-bearing supported treadmill training for patients with acute incomplete spinal cord injury: a pilot study. Arch Phys Med Rehabil. 2004:85(4):604-10.

11. Ambrosini E, Ferrante S, Pedrocchi A, Ferrigno G, Molteni F. Cycling induced by electrical stimulation improves motor recovery in postacute hemiparetic patients: a randomized controlled trial. Stroke. 2011;42(4):1068-73.

12. McDonald JW, Becker D, Sadowsky CL, Jane JA Sr, Conturo TE, Schultz LM. Late recovery following spinal cord injury. Case report and review of the literature. J Neurosurg. 2002:97(2 Suppl):252-65.

13. Sadowsky CL, Hammond ER, Strohl AB, Commean PK, Eby SA, Damiano DL, et al. Lower extremity functional electrical stimulation cycling promotes physical and functional recovery in chronic spinal cord injury. J Spinal Cord Med. 2013;36(6):623-31

14. Yasar E, Yilmaz B, Goktepe S, Kesikburun S. The effect of functional electrical stimulation cycling on late functional improvement in patients with chronic incomplete spinal cord injury. Spinal Cord. 2015;53(12):900.

15. Prior MM, Stinear JW. Phasic spike-timing-dependent plasticity of human motor cortex during walking. Brain Res. 2006;1110(1):150-8.

16. Urbin MA, Ozdemir RA, Tazoe T, Perez MA. Spike-timing-dependent plasticity in lower-limb motoneurons after human spinal cord injury. Neurophysiol. 2017;118(4):2171-80 
17. Jochumsen M, Niazi IK, Signal N, Nedergaard RW, Holt K, Haavik H, et al. Pairing voluntary movement and muscle-located electrical stimulation increases cortical excitability. Front Hum Neurosci. 2016;10:482.

18. Rushton DN. Functional electrical stimulation and rehabilitation--an hypothesis. Med Eng Phys. 2003;25(1):75-8.

19. Gandolla M, Ferrante S, Molteni F, Guanziroli E, Frattini T, Martegani A, et al. Re-thinking the role of motor cortex: context-sensitive motor outputs? Neurolmage. 2014;91:366-74.

20. Gandolla M, Ward NS, Molteni F, Guanziroli E, Ferrigno G, Pedrocchi A. The neural correlates of long-term carryover following functional electrical stimulation for stroke. Neural Plast. 2016;2016:4192718.

21. Luo R. Can the Voluntary Drive to a Paretic Muscle be Estimated from the Myoelectric Signal during Stimulation? Doctoral Thesis, UCL (University College London). 2013. https://discovery.ucl.ac.uk/id/eprint/1409755.

22. Marino RJ, Ditunno JF Jr, Donovan WH, Maynard F Jr. Neurologic recovery after traumatic spinal cord injury: data from the model spinal cord injury systems. Arch Phys Med Rehabil. 1999;80(11):1391-6.

23. Geisler FH, Coleman WP, Grieco G, Poonian D. Measurements and recovery patterns in a multicenter study of acute spinal cord injury. Spine. 2001;26(24 Suppl):S68-86.

24. Fawcett JW, Curt A, Steeves JD, Coleman WP, Tuszynski MH, Lammertse D, et al. Guidelines for the conduct of clinical trials for spinal cord injury as developed by the ICCP panel: spontaneous recovery after spinal cord injury and statistical power needed for therapeutic clinical trials. Spinal Cord. 2007; 45(3):190-205.

25. Morrison SA, Lorenz D, Eskay CP, Forrest GF, Basso DM. Longitudinal recovery and reduced costs after 120 sessions of Locomotor training for motor incomplete spinal cord injury. Arch Phys Med Rehabil. 2018;99(3):555-62.

26. Wagner FB, Mignardot JB, Le Goff-Mignardot CG, Demesmaeker R, Komi S, Capogrosso M, et al. Targeted neurotechnology restores walking in humans with spinal cord injury. Nature. 2018;563(7729):65-71.

27. Duchateau J, Enoka RM. Neural control of shortening and lengthening contractions: influence of task constraints. J Physiol. 2008;586(24):5853-64.

28. Onifer SM, Smith GM, Fouad K. Plasticity after spinal cord injury: relevance to recovery and approaches to facilitate it. Neurotherapeutics. 2011;8(2): 283-93.

29. Martin R, Sadowsky C, Obst K, Meyer B, McDonald J. Functional electrical stimulation in spinal cord injury:: from theory to practice. Topics Spin Cord Injury Rehabil. 2012;18(1):28-33.

30. Hitzig SL, Eng JJ, Miller WC, Sakakibara BM. An evidence-based review of aging of the body systems following spinal cord injury. Spinal Cord. 2011; 49(6):684-701.

31. Sadowsky CL, McDonald JW. Activity-based restorative therapies: concepts and applications in spinal cord injury-related neurorehabilitation. Dev Disabil Res Rev. 2009;15(2):112-6.

32. Crameri RM, Weston A, Climstein M, Davis GM, Sutton JR. Effects of electrical stimulation-induced leg training on skeletal muscle adaptability in spinal cord injury. Scand J Med Sci Sports. 2002;12(5):316-22.

33. Mohr T, Andersen JL, Biering-Sorensen F, Galbo H, Bangsbo J, Wagner A, et al. Long-term adaptation to electrically induced cycle training in severe spinal cord injured individuals. Spinal Cord. 1997;35(1):1-16.

34. Frotzler A, Coupaud S, Perret C, Kakebeeke TH, Hunt K, Donaldson NN, et al. High-volume FES-cycling partially reverses bone loss in people with chronic spinal cord injury. Bone. 2008;43(1):169-76.

35. Duffell LD, Donaldson NN, Newham DJ. Power output during functional electrically stimulated cycling in trained spinal cord injured people. Neuromodulation. 2010;13(1):50-7.

36. Rossini PM, Caramia MD, Zarola F. Mechanisms of nervous propagation along central motor pathways: noninvasive evaluation in healthy subjects and in patients with neurological disease. Neurosurgery. 1987;20(1):183-91.

37. Boorman G, Becker WJ, Morrice BL, Lee RG. Modulation of the soleus Hreflex during pedalling in normal humans and in patients with spinal spasticity. J Neurol Neurosurg Psychiatry. 1992;55(12):1150-6.

38. Boorman GI, Lee RG, Becker WJ, Windhorst UR. Impaired "natural reciprocal inhibition" in patients with spasticity due to incomplete spinal cord injury. Electroencephalogr Clin Neurophysiol. 1996;101(2):84-92.

\section{Publisher's Note}

Springer Nature remains neutral with regard to jurisdictional claims in published maps and institutional affiliations.

Ready to submit your research? Choose BMC and benefit from:

- fast, convenient online submission

- thorough peer review by experienced researchers in your field

- rapid publication on acceptance

- support for research data, including large and complex data types

- gold Open Access which fosters wider collaboration and increased citations

- maximum visibility for your research: over $100 \mathrm{M}$ website views per year

At BMC, research is always in progress.

Learn more biomedcentral.com/submissions 